\title{
Association of diabetes-related self-care activities with glycemic control of patients with type 2 diabetes in Pakistan
}

\begin{abstract}
Allah Bukhsh,, ${ }^{1,2}$ Tahir Mehmood Khan, 1,2 Muhammad Sarfraz Nawaz, ${ }^{3}$ Hafiz Sajjad Ahmed, ${ }^{4}$ Kok Gan Chan, ${ }^{5,6}$ Learn-Han Lee, 1,2,7-10 Bey-Hing Goh ${ }^{1,2,7-10}$

'School of Pharmacy, Monash University, Jalan Lagoon Selatan 45700, Selangor, Malaysia; Institute of Pharmaceutical Sciences, University of Veterinary and Animal Sciences, 54000, Lahore, Pakistan; ${ }^{3}$ Department of Pharmacy, Quaid-i-Azam University Islamabad, Pakistan; ${ }^{4}$ Capital Hospital Islamabad, Pakistan; ${ }^{5}$ International Genome Centre, Jiangsu University, Zhenjiang, China; ${ }^{6}$ Division of Genetics and Molecular Biology, Faculty of Science, Institute of Biological Sciences, University of Malaya, Kuala Lumpur, Malaysia; ${ }^{7}$ Asian Centre for Evidence Synthesis in Population, Implementation and Clinical Outcomes (PICO), Health and Well-being Cluster, Global Asia in the 21 st Century (GA2I) Platform, Monash University Malaysia, Bandar Sunway, Selangor, Malaysia; ${ }^{8}$ Novel Bacteria and Drug Discovery Research Group, Microbiome and Bioresource Research Strength, Jeffrey Cheah School of Medicine and Health Sciences, Monash University Malaysia, Bandar Sunway, Malaysia; ${ }^{9}$ Biofunctional Molecule Exploratory Research Group, School of Pharmacy, Monash University Malaysia, Bandar Sunway, Malaysia; ${ }^{10}$ Center of Health Outcomes Research and Therapeutic, Safety (Cohorts), School of Pharmaceutical Sciences, University of Phayao, Mueang Phayao, Thailand
\end{abstract}

Correspondence: Allah Bukhsh

School of Pharmacy, Monash University, Jalan Lagoon Selatan 45700, Selangor, Malaysia

Tel +92333409 059l

Email abukhsh@uvas.edu.pk

Kok Gan Chan

Division of Genetics and Molecular Biology, Institute of Biological Sciences, Faculty of Science, University of Malaya, 50603 Kuala Lumpur, Malaysia Tel +6037967 7748

Email kokgan@um.edu.my
This article was published in the following Dove Press journal:

Patient Preference and Adherence

Objective: Association of various self-care activities on glycemic control of people with diabetes (PWD) in Pakistan is yet to be explored. The current study aimed to evaluate the association of various diabetes-related self-care activities with glycated hemoglobin (HbA1c) levels and to examine the predictive relationship of patients' demographic variables with their self-care activities.

Patients and methods: A cross-sectional study was conducted on adult PWD ( $=218$ ) who were diagnosed with type 2 diabetes mellitus of at least 1 year duration. Self-care activities were examined by using the Urdu version of Diabetes Self-management Questionnaire. Linear regression analysis was conducted to examine the significant predictors for diabetes-related self-care activities and glycemic control.

Results: Mean age of the patients was $50.77 \pm 13.3$ years. Poor glycemic control (HbA1c $\geq 7 \%$ ) was observed in majority of the patients $(83 \%)$. Linear regression analysis revealed that glucose management $(\beta=-0.44 ; 95 \% \mathrm{CI}-0.438,-0.209 ; P<0.001)$ was the strongest predictor for low levels of patients' HbA1c, followed by dietary control $(\beta=-0.19 ; 95 \% \mathrm{CI}-0.248,-0.018$; $P=0.024)$ and physical activity $(\beta=-0.17 ; 95 \% \mathrm{CI}-0.165,-0.023 ; P=0.010)$, respectively. Linear regression analysis showed that use of oral hypoglycemic agents only $(\beta=-0.218$; $95 \% \mathrm{CI}-0.956,-0.200 ; P=0.003)$ and higher education level $(\beta=0.204 ; 95 \% \mathrm{CI} 0.138,0.777$; $P=0.005$ ) were significant predictors for higher scores of patients' self-care activities.

Conclusion: The findings support that PWD having better self-reported self-care activities achieve better glycemic control. Patients' self-care activities should be monitored on a regular basis, especially for those who are at risk of poor glycemic control.

Keywords: self-care, self-management, glycemic control, glycated hemoglobin

\section{Introduction}

According to the International Diabetes Federation Diabetes Atlas, 425 million are suffering from diabetes worldwide, and it is a rapidly growing global health issue. ${ }^{1}$ Pakistan has the second highest number of diabetes patients (7.028 million) in the Middle East and North Africa International Diabetes Federation region, with a prevalence rate of $6.9 \% .^{2}$

Type 2 diabetes mellitus (T2DM) is a chronic disease; in addition to significant mortality rate, it can result in serious comorbid conditions. ${ }^{3}$ If not properly controlled, diabetes can lead to increased risk of many complications, such as diabetic nephropathy, diabetic neuropathy, heart disease, stroke, leg amputation and even early death. ${ }^{4}$ Delaying the progression of diabetes will lead to improved health and economic outcomes of patients, society and the health care system. ${ }^{5}$ Diabetes-associated potential 
complications can be avoided if optimum glycemic control is achieved. Although the importance of glycemic control in diabetes patients is well established, as many studies have reported a significant reduction in the incidence of diabetesrelated complications, but often it is not achieved. .,7 $^{6}$

Diabetes is also known as a self-managed disease as majority of the care in this disease is provided by patients themselves; so, it requires patients' commitment and abilities to carry out self-care in their routine life. ${ }^{8}$ Self-care activities in people with diabetes (PWD) include healthy diet, being physically active, self-monitoring of blood glucose and regular intake of medicines. ${ }^{9-14}$ Daily self-care activities play a key role in achieving diabetes-related positive health outcomes, and clinically significant association between glycemic control and self-care activities has been reported in many studies. ${ }^{15,16}$ Literature reports indicate that the studies which have been conducted so far in Pakistan had examined the status of glycemic control in PWD; ${ }^{17,18}$ however, little has been done to assess the association of self-care activities with glycemic control. Glycemic control is defined as the level of glycated hemoglobin (HbA1c) being $<7 \%$. In view of understanding the role of self-care activities on glycemic control, this study aimed to 1) evaluate the predictive relationship of diabetes-related self-care activities to HbA1c levels of PWD and 2) examine the possible association between participants' demographic variables and diabetes-related self-care activities. The hypothesis of the present study is that, as the self-care activities increase, the levels of $\mathrm{HbA} 1 \mathrm{c}$ decrease.

\section{Patients and methods}

This cross-sectional study was conducted using the validated Urdu version of Diabetes Self-management Questionnaire (DSMQ; ${ }^{19}$ English and Urdu versions of DSMQ are freely available online, and the web addresses are given at the end of the manuscript). The tools were used in PWD $(\mathrm{N}=218)$ at Capital Hospital Islamabad, Akhuwat Diabetes Clinic Lahore and Awan Medical Complex Lahore after seeking prior approval from the authors. The interviews were conducted in simple Urdu language, which is the national language of Pakistan and is widely spoken and understood by the general Pakistani population.

\section{Study population}

To participate in the interview, patients had to be $>30$ years of age, diagnosed with T2DM for $>1$ year, should have done a recent $\mathrm{HbA} 1 \mathrm{c}$ lab test (not more than 8 weeks before the date of interview), should be able to speak and understand
Urdu and should not be suffering from terminal illness and cognitive impairment. Participation in the study was voluntary and informed consent was obtained from all participants after providing them detailed information about the study objectives and procedure.

\section{Sample size}

The sample size calculated for this study was 202, based on the diabetes prevalence of $6.9 \%$ in Pakistan, ${ }^{2}$ using Daniel (1999) formula for sample size. ${ }^{20}$

$$
\mathrm{n}=\frac{Z^{2} \mathrm{P}(1-\mathrm{P})}{\mathrm{d}^{2}}
$$

where $\mathrm{n}$ is the population sample size, $Z$ is the statistic for a level of confidence, $\mathrm{P}$ is the expected prevalence or proportion and $\mathrm{d}$ is the precision.

The prevalence of diabetes in Pakistan is $6.9 \%,{ }^{2}$ so $P=0.069$, while $Z=1.96$ (for $95 \%$ level of confidence) and $\mathrm{d}=0.035$. The patients' sample size for Pakistan was 202 . However, data were collected from 230 patients in order to compensate for the incomplete questionnaires.

\section{Ethical consideration}

The ethics approval for the current study was obtained from Monash University Human Research and Ethics (Ethics approval No 7767, dated 01-02-2017), after seeking permissions for data collection from the health care facilities at Pakistan.

\section{Sample recruitment and data collection}

The data were collected from February 2017 to September 2017. Eligible patients for the study were identified by reviewing their medical records and with the help of physicians from diabetes care clinic. Those PWD who met the inclusion criteria were approached by the researcher physically to seek their consent to participate in the study after explaining to them the study objectives and procedure, while patients were waiting to seek consultation from their physicians. Researchers and/or research assistants collected data about patients' demographics and administered the Urdu version of $\mathrm{DSMQ}^{21}$ to the eligible PWD who were willing to participate in the study. If required, the items of DSMQ study tool were read out and explained to the participants by the investigators. Two hundred and forty-five patients agreed to participate in the study; $n=230$ patients filled the questionnaires (response rate $93.7 \%$ ) and after excluding the incomplete questionnaires, $\mathrm{N}=218$ patients' data were analyzed in this study. 


\section{Study tools}

\section{Patients' demographic information}

The patients' demographic characteristics, such as age (years), gender, smoking status, education, family history of diabetes, duration of diabetes, nature of euglycemic agents and lab data, were collected on the patients' demographic and lab data collection form.

\section{DSMQ}

Patients' diabetes-related self-care activities were measured by using the Urdu version of DSMQ. ${ }^{19}$ This tool was designed to examine the association of diabetes patients' self-care activities with their glycemic control. ${ }^{22}$

This questionnaire has been validated in Urdu language in PWD from Pakistan. ${ }^{19}$ This tool with 16 self-care items has four subscales as follows: 1) Glucose Management (GM), consisting of five statements: 1, 4, 6, 10,12, which are related to medication adherence and blood glucose monitoring; 2) Dietary Control (DC), consisting of four statements: $2,5,9,13$, which are related to diabetes-associated dietary management behaviors; 3) Physical Activity (PA) consisting of three statements: $8,11,15$, which are related to exercise or activity for management of diabetes and 4) Health Care Use (HU) consisting of three statements: $3,7,14$, which are related to adherence to diabetes-related physicians' appointments. The last item (item 16) requires the respondents to rate their overall diabetes self-care, hence its score is included only in the "sum scale".

The scoring process of the DSMQ involves adding up the scores of all 16 items after reversing the scores of nine negatively keyed statements. Higher scores will represent more effective self-care. Finally, the DSMQ scores will be transformed to a scale ranging from 0 to 10 , where a score of 10 will indicate the most effective self-care behavior.

\section{Statistical analyses}

The relationship of patient demographic characteristics and self-care practices was assessed with their glycemic control, which was defined according to American Diabetes Association guidelines as follows: good control $\mathrm{HbAlc}<7 \%$ and poor control $\mathrm{HbA} 1 \mathrm{c} \geq 7 \% .{ }^{23-25}$ Collected data were transcribed into English language and then analyzed using SPSS (24.0; IBM Corporation, Armonk, NY, USA). The significance level was set at $P<0.05$.

Descriptive statistics were used to calculate percentages, frequencies, means and SD or median and IQR. The relationship between patients' demographic variables and glycemic control (categorical data) was determined using chi-squared test. Fisher's exact test was applied in cases where the cell count was less than five. Shapiro-Wilk test was applied to check the distribution of data. ${ }^{26}$ Depending on the data distribution, either Pearson's correlation or Spearman's rank order (two-tailed test) was applied to verify the existence of a correlation between instruments' mean scores and other values. Comparisons between groups with non-normal distribution were performed using the Mann-Whitney $U$ test and the Kruskal-Wallis test.

The association of $\mathrm{HbA1c}$ with the DSMQ sum scale and its subscales (GM, DC, PA and HU) was examined by linear regression. Significant demographic predictors of the patients for self-care activities were identified by using multiple linear regression.

\section{Results}

Data of $\mathrm{N}=218$ patients were analyzed. Mean age of the participants was $50.77 \pm 13.3$ years, with $23.4 \%$ being $>60$ years. About half were men (51.4\%), and majority of the participants were married (97.7\%). Only $20.6 \%$ had university level education or above, whereas $22 \%$ had no formal education. Mean diabetes duration was $6.8 \pm 6.3$ years, and almost half the participants $(49.5 \%)$ had diabetes of duration $<5$ years.

More than half of the participants $(59.2 \%)$ had family history of diabetes in their first-degree relatives. Around half $(52.8 \%)$ of the participants were taking oral hypoglycemic agents (OHA) for their diabetes management. Detailed demographic characteristics and their association with glycemic control are presented in Table 1. None of the patients' demographic variable was significantly associated with glycemic control.

Patients with good glycemic control (HbAlc $<7 \%)$ scored significantly higher $(P<0.01)$ for self-care activities (DSMQ sum-scale score 7.71; IQR 6.97-8.85), as compared to patients with poor glycemic control (DSMQ sum-scale score 3.54; IQR 2.71-5.21). Patients' education, smoking status and nature of antihyperglycemic therapy were also significantly $(P<0.01)$ associated with their self-care activities, as shown in Table 2.

Strongly negative correlation was observed between DSMQ sum scale $(r=-0.77, P<0.001)$ and its four subscales, namely, GM $(r=-0.74, P<0.001)$, DC $(r=-0.69, P<0.001)$, PA $(r=-0.64, P<0.001)$ and HU $(r=-0.66, P<0.001)$, with patients' HbA1c levels. Similarly, results of Mann-Whitney $U$ test, scores of DSMQ sum scale and its four subscales were significantly higher in patients with good glycemic control (Table 3). 
Table I Characteristics of the study sample and their association with glycemic control $(\mathrm{N}=2$ I 8$)$

\begin{tabular}{|c|c|c|c|c|c|}
\hline Parameters & Mean \pm SD & n (\%) & $\begin{array}{l}\text { Good glycemic } \\
\text { control (<7\%), } \\
\mathbf{n = 3 7}(\mathbf{I} \%)\end{array}$ & $\begin{array}{l}\text { Poor glycemic } \\
\text { control }(>7 \%) \text {, } \\
n=|8|(83 \%)\end{array}$ & $P$-value \\
\hline Gender & & & & & $0.20^{\mathrm{a}}$ \\
\hline Male & & $\mathrm{II} 2(5 \mathrm{I} .4)$ & $23(62.2)$ & $89(49.2)$ & \\
\hline Female & & $106(48.6)$ & $14(37.8)$ & $92(50.8)$ & \\
\hline Age (years) & $50.77 \pm 13.3$ & & & & $0.96^{\mathrm{b}}$ \\
\hline $30-45$ & & $65(29.8)$ & $14(37.8)$ & $5 \mathrm{I}(28.2)$ & $0.29^{a}$ \\
\hline$>45-60$ & & $102(48.8)$ & $13(35.1)$ & $89(49.2)$ & \\
\hline$>60$ & & $51(23.4)$ & $10(27)$ & $4 I(22.7)$ & \\
\hline Marital status & & & & & $0.99^{\circ}$ \\
\hline Single & & $4(1.8)$ & 0 & $4(2.2)$ & \\
\hline Married & & $213(97.7)$ & $37(100)$ & $176(97.2)$ & \\
\hline Divorced & & $\mathrm{I}(0.5)$ & 0 & I $(0.6)$ & \\
\hline BMI $\left(\mathrm{kg} / \mathrm{m}^{2}\right)$ & $29.51 \pm 6.9$ & & & & $0.64^{b}$ \\
\hline Underweight $(<\mid 8.5)$ & & $3(1.4)$ & 0 & $3(1.7)$ & $0.94^{c}$ \\
\hline Normal (I8.5-24.9) & & 51 (22.9) & $8(21.6)$ & $43(23.8)$ & \\
\hline Overweight (25-29.9) & & $85(38.5)$ & $17(49.9)$ & $68(37.6)$ & \\
\hline Obese $(>30)$ & & $79(37.2)$ & $12(32.4)$ & $67(37.0)$ & \\
\hline Smoking & & & & & $0.70^{c}$ \\
\hline No & & $206(94.5)$ & $36(97.7)$ & $169(93.4)$ & \\
\hline Yes & & $12(5.5)$ & $\mathrm{I}(2.7)$ & $12(6.6)$ & \\
\hline Education & & & & & $0.5 \mathrm{I}^{\mathrm{a}}$ \\
\hline No formal education & & $48(22)$ & $7(18.9)$ & 41 (22.7) & \\
\hline Primary level & & $37(17)$ & $6(16.2)$ & $31(17.1)$ & \\
\hline Secondary level & & $88(40.4)$ & $13(35.1)$ & $75(41.4)$ & \\
\hline University level & & $45(20.6)$ & II (29.7) & $34(18.8)$ & \\
\hline Working status & & & & & $0.18^{c}$ \\
\hline Jobless & & $8(3.7)$ & 0 & $8(4.4)$ & \\
\hline Housewife/stay at home & & $104(47.7)$ & $14(37.8)$ & $90(49.7)$ & \\
\hline Businessman & & $33(15.1)$ & $4(10.8)$ & $29(16)$ & \\
\hline Private job & & $47(21.6)$ & $12(32.4)$ & $35(19.3)$ & \\
\hline Government job & & $12(5.5)$ & $3(8.1)$ & $9(5)$ & \\
\hline Retired & & $14(6.4)$ & $4(10.8)$ & $10(5.5)$ & \\
\hline Diabetes duration (years) & $6.8 \pm 6.3$ & & & & $0.67^{b}$ \\
\hline$<5$ & & $108(49.5)$ & $23(62.2)$ & $85(47)$ & $0.16^{c}$ \\
\hline $5-9$ & & $44(20.2)$ & $8(21.6)$ & $36(19.9)$ & \\
\hline$>9-<15$ & & $4 I(18.8)$ & $5(13.5)$ & $36(19.9)$ & \\
\hline$\geq 15$ & & $25(11.5)$ & $\mathrm{I}(2.7)$ & $24(13.3)$ & \\
\hline Family history of diabetes & & & & & $0.66^{c}$ \\
\hline First-degree relatives & & $129(59.2)$ & $20(54.1)$ & $109(60.2)$ & \\
\hline Second-degree relatives & & $3(1.4)$ & I (2.7) & $2(1 . I)$ & \\
\hline Both first and second & & $17(7.8)$ & $3(8.1)$ & $14(7.7)$ & \\
\hline No history & & $69(31.7)$ & $13(35.1)$ & $56(30.9)$ & \\
\hline Antidiabetic therapy & & & & & $0.29^{c}$ \\
\hline Exclusively insulin & $36(16.5)$ & $4(10.8)$ & $32(17.7)$ & & \\
\hline Combined with medication & $67(30.7)$ & $9(24.3)$ & $58(32)$ & & \\
\hline OHA only & $115(52.8)$ & $24(64.9)$ & $91(50.3)$ & & \\
\hline
\end{tabular}

Notes: Data are $\mathrm{n}(\%)$ or mean \pm SD. ${ }^{2}$ Chi-squared association between patients' demographic variables and glycemic control. 'Pearson's correlations (two-tailed test) between patients' demographic variables and their HbAlc levels. 'Fisher's exact test was used to determine the association between patients' demographic variables and glycemic control.

Abbreviations: BMI, body mass index; HbAlc, glycated hemoglobin; OHA, oral hypoglycemic agents. 
Table 2 Association of diabetes self-management practices of type 2 diabetes patients with their demographic characteristics ( $\mathrm{N}=2$ I8)

\begin{tabular}{|c|c|c|c|}
\hline Parameters & n (\%); median (IQR) & $\begin{array}{l}\text { DSMQ sum score } \\
\text { Median (IQR) }\end{array}$ & $P$-value \\
\hline Gender & & & $0.24^{a}$ \\
\hline Male & $112(5 \mid .4)$ & $3.95(2.96-7.24)$ & \\
\hline Female & $106(48.6)$ & $3.75(2.7 \mathrm{I}-6.35)$ & \\
\hline Age (years) & $52(45-60)$ & & $0.55^{\mathrm{b}}$ \\
\hline $30-45$ & $65(29.8)$ & $3.96(3.12-7.08)$ & \\
\hline$>45-60$ & $102(48.8)$ & $3.75(2.7 \mathrm{I}-6.93)$ & \\
\hline$>60$ & $51(23.4)$ & $3.96(2.5-6.25)$ & \\
\hline BMI $\left(\mathrm{kg} / \mathrm{m}^{2}\right)$ & $28.53(24.99-32.32)$ & & $0.40^{\mathrm{b}}$ \\
\hline Underweight $(<18.5)$ & $3(1.4)$ & $3.54(2.29-3.54)$ & \\
\hline Normal $(18.5-<25)$ & $51(22.9)$ & $3.33(2.5-6.87)$ & \\
\hline Overweight $(25-<30)$ & $85(38.5)$ & $4.37(3.12-6.98)$ & \\
\hline Obese $(\geq 30)$ & $79(37.2)$ & $3.95(2.92-7.08)$ & \\
\hline Smoking & & & $0.004^{\mathrm{a}}$ \\
\hline No & $206(94.5)$ & $3.96(2.92-7.08)$ & \\
\hline Yes & $13(5.5)$ & $2.5(1.35-4.38)$ & \\
\hline Education & & & $0.00 \mathrm{I}^{\mathrm{b}}$ \\
\hline No formal education & $48(22)$ & $3.64(2.34-5.57)$ & \\
\hline Primary level & $37(17)$ & $3.75(2.60-5.63)$ & \\
\hline Secondary level & $88(40.4)$ & $3.75(2.81-7.29)$ & \\
\hline University level & $45(20.6)$ & $5.21(3.33-7.92)$ & \\
\hline Family history of diabetes & & & $0.32^{\mathrm{b}}$ \\
\hline First-degree relatives & $129(59.2)$ & $3.96(2.92-7.08)$ & \\
\hline Second-degree relatives & $3(1.4)$ & $2.29(2.29-2.29)$ & \\
\hline Both first- and second-degree relatives & $17(7.8)$ & $5.63(3.44-7.50)$ & \\
\hline No history & $69(31.7)$ & $3.75(2.50-6.25)$ & \\
\hline Diabetes duration (years) & $5(2-10)$ & & $0.74^{b}$ \\
\hline$<5$ & $108(49.5)$ & $3.96(2.96-6.88)$ & \\
\hline $5-9$ & $44(20.2)$ & $3.64(2.7 \mathrm{I}-7.50)$ & \\
\hline$>9-<15$ & $4 I(18.8)$ & $3.75(2.7 \mid-6.14)$ & \\
\hline$\geq 15$ & $25(11.5)$ & $3.96(2.60-5.62)$ & \\
\hline Antidiabetic therapy & & & $<0.00 I^{b}$ \\
\hline Exclusively insulin & $36(16.5)$ & $3.75(2.5-6.67)$ & \\
\hline Combined with medication & $67(30.7)$ & $3.33(2.50-5.21)$ & \\
\hline Oral hypoglycemic agents only & $115(52.8)$ & $4.79(3.33-7.50)$ & \\
\hline HbA Ic value (\%) & $8.9(7.27-10.2)$ & & $<0.00 I^{a}$ \\
\hline Good glycemic control $(<7 \%)$ & $37(17)$ & $7.71(6.97-8.85)$ & \\
\hline Poor glycemic control ( $\geq 7 \%$ ) & $18 \mid(83)$ & $3.54(2.7 I-5.2 I)$ & \\
\hline
\end{tabular}

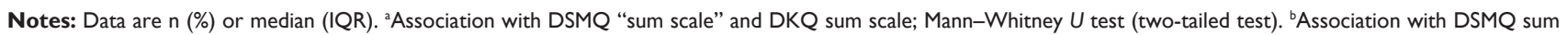
scale and DKQ sum scale; Kruskal-Wallis test.

Abbreviations: BMI, body mass index; DKQ, Diabetes Knowledge Questionnaire; DSMQ, Diabetes Self-management Questionnaire; HbAlc, glycated hemoglobin.

Linear regression analysis indicated that $\mathrm{GM}$ was the strongest predictor for patients' low levels of $\mathrm{HbA1c}(\beta=-0.44$; $95 \%$ CI $-0.438,-0.209 ; P<0.010)$, followed by DC $(\beta=-0.19$; $95 \% \mathrm{CI}-0.248,-0.018 ; P<0.05)$ and PA $(\beta=-0.17 ; 95 \%$ $\mathrm{CI}-0.165,-0.023 ; P<0.05)$. However, $\mathrm{HU}$ was a poor predictor for low HbA1c levels. Details are presented in Table 4.
Multiple linear regression analysis was conducted to identify patients' demographic predictors for diabetes-related self-care activities (DSMQ sum-scale score). Regression analysis showed that patients' smoking status $(\beta=-0.200$; $95 \%$ CI $-3.265,-0.701)$, nature of euglycemic medicine $(\beta=-0.218 ; 95 \% \mathrm{CI}-0.956,-0.200)$ and level of respondent's 
Table 3 Association of glycemic control with self-management practices $(\mathrm{N}=218)$

\begin{tabular}{|c|c|c|c|c|}
\hline \multirow[t]{2}{*}{ Parameters } & \multirow[t]{2}{*}{ Median (IQR) } & \multirow[t]{2}{*}{ Correlation $^{a}$} & \multicolumn{2}{|c|}{ Glycemic control $^{b}$} \\
\hline & & & $<7 \%(n=37)$ & $\geq 7 \%(n=181)$ \\
\hline DSMQ sum scale & $3.96(2.71-6.88)$ & $-0.77 * * *$ & $7.71(6.97-8.85)$ & $3.54(2.7 I-5.2 I)^{* *}$ \\
\hline \multicolumn{5}{|l|}{ Subscales } \\
\hline Glucose Management & $4.67(3.33-7.33)$ & $-0.74 * * *$ & $8.67(7.33-9.33)$ & $4.00(3.33-6.00)^{* * *}$ \\
\hline Dietary Control & $4.17(2.5-6.88)$ & $-0.69 * * *$ & 7.5 (6.67-9.17) & $3.33(2.50-5.83)^{* *}$ \\
\hline Physical Activity & $3.33(1.11-6.67)$ & $-0.64 * * *$ & $7.78(6.67-8.89)$ & $3.33(1.11-5.56)^{* * * *}$ \\
\hline Health-Care Use & $4.44(2.22-6.67)$ & $-0.66 * * *$ & $6.67(5.56-7.78)$ & $3.33(2.22-5.56)^{* *}$ \\
\hline
\end{tabular}

Notes: aSpearman's rank order (two-tailed test) for DSMQ scales with HbAlc. bMann-Whitney $U$ test for the association of DSMQ scales with HbAlc. ***P $<0.00 \mathrm{I}$; **P $<0.01$. The DSMQ scale scores are transformed to a scale ranging from 0 to 10.

Abbreviation: DSMQ, Diabetes Self-Management Questionnaire.

education ( $\beta=0.204 ; 95 \%$ CI $0.138,0.777)$ were significant predictors for their self-care activities. Whereas, patients' gender, age, nature of job and duration of diabetes were found to be insignificant predictors for patients' self-care activities. The details are presented in Table 5 .

\section{Discussion}

Diabetes is becoming a serious health problem, especially in low- and middle-income countries such as Pakistan. Efficient management is required to achieve the objective of glycemic control in order to minimize the progression of disease and associated complications.

Majority of the participants in this study had poor glycemic control; only $17 \%$ were reported to have good glycemic control, which is even lower to what was reported in other studies from two major cities (Rawalpindi and Peshawar) of Pakistan, where good glycemic control was observed in $30 \%$ and $31.43 \%$ of the studied PWD, respectively. ${ }^{17}$

There could be many factors contributing toward achieving the ideal glycemic control. Patient's self-care activities could be one of the major factors behind this. The results of this study revealed a strong negative correlation between self-care activities score and HbA1c levels of PWD. This

Table 4 Linear association of DSMQ sum scale and subscales with $\mathrm{HbAlc}$ of type 2 diabetes patients $(\mathrm{N}=2 \mid 8) ; R^{2}=0.62$

\begin{tabular}{|l|l|l|}
\hline Predictors & $\boldsymbol{\beta}(\mathbf{9 5} \% \mathbf{C l})$ & $\boldsymbol{P}$-value \\
\hline DSMQ sum scale & $-0.64(-0.557,-0.393)$ & $<0.00 \mathrm{I}$ \\
\hline DC & $-0.19(-0.248,-0.018)$ & 0.024 \\
\hline GM & $-0.44(-0.438,-0.209)$ & $<0.001$ \\
\hline PA & $-0.17(-0.165,-0.023)$ & 0.010 \\
\hline HU & $-0.05(-0.14 I, 0.273)$ & 0.473 \\
\hline
\end{tabular}

Abbreviations: DC, Dietary Control; DSMQ, Diabetes Self-Management Questionnaire; GM, Glucose Management; HbAlc, glycated hemoglobin; HU, Health Care Use; PA, Physical Activity. finding is in line with our hypothesis, as patients with higher DSMQ scores were expected to perform better self-care behavior and thus had better glycemic control. The results of our study conform to the results from other low- and middle-income countries, as well as high-income countries, that poor glycemic control is associated with poor self-care practices of the patient. ${ }^{27,28}$

In the present study, linear regression analysis revealed that GM, which includes medication intake and regular selfmonitoring of blood glucose level, was the most significant predictor for low HbA1c levels, followed by DC and PA, whereas $\mathrm{HU}$ was observed to be the least predictor for low HbAlc levels.

Diet plays an important role in controlling the blood glucose levels and disease progression. Diet was observed as a significant predictor for glycemic control in PWD. Although majority of the patients did not score high for DC for their diabetes, those who scored high had good glycemic control. Many interventional studies had shown the benefi-

Table 5 Linear association of patients' demographic characteristics on DSMQ sum scale $(\mathrm{N}=218)$

\begin{tabular}{|l|l|l|}
\hline Predictors & $\beta(95 \% \mathbf{C l})$ & $P$-value \\
\hline Gender & $-0.130(-1.609,0.39 I)$ & $0.23 \mathrm{I}$ \\
\hline Working status & $0.176(-0.047,0.527)$ & $0.10 \mathrm{I}$ \\
\hline Antidiabetes medication & $-0.218(-0.956,-0.200)$ & 0.003 \\
\hline Education & $0.204(0.138,0.777)$ & 0.005 \\
\hline Duration of diabetes (years) & $0.054(-0.206,0.442)$ & 0.474 \\
\hline Age (years) & $-0.015(-0.499,0.399)$ & 0.827 \\
\hline Smoking & $-0.200(-3.265,-0.70 \mathrm{I})$ & 0.003 \\
\hline
\end{tabular}

Notes: Gender (reference category = female); working status (reference category= jobless); antidiabetes medication (reference category = oral hypoglycemic agents); education (reference category = no formal education); and smoking (reference category $=$ no smoking).

Abbreviation: DSMQ, Diabetes Self-Management Questionnaire. 
cial outcome of dietary educational programs on patients' glycemic control..$^{29}$ As no standard diet plan works for all patients, health care professionals should instead provide patient-tailored recommendations, taking into account their affordability, personal and cultural preferences.

Inadequate practice of exercise was evident from the low median scores of patients' PA. It was observed in our study that patients with good glycemic control scored significantly higher for PA as compared to patients with poor glycemic control. According to a similar study conducted at one of the major cities of Pakistan, around $75 \%$ of the respondents with diabetes (duration $>9$ years) did not perform any sort of physical activity to control their blood glucose levels. ${ }^{30}$

Besides the self-care practices, patients' demographic factors could also influence the glycemic control, such as duration of disease. Diabetes is a progressive disease and one of the possibilities could be that euglycemic therapy is not being suitably intensified in patients with longer duration of disease, as $\sim 50 \%$ of the study respondents with poor glycemic control were on OHA only.

In this study, we also observed the predictive value of patients' demographic characteristics for their self-care practices. Higher level of patient's education was a strong predictor for good self-care practices, which is similar to the findings of previous studies conducted in low- and middleincome countries. ${ }^{31-34}$ In the present study, only $21 \%$ of the participants who had university level education had maximum score for diabetes-related self-care practices, which indicated that educated people have more self-care behaviors and good glycemic control. A similar trend was observed in Ethiopia by Kassahun et al, where poor self-care behavior was observed in respondents with lower educational levels. ${ }^{31}$

Patients who were using OHA in combination with insulin had poor self-care practices in comparison to the patients who were taking either OHA or insulin alone. Several other studies had also reported the nature of euglycemic medication as a significant predictor. ${ }^{35-37}$

Diabetes is known as a self-managed disease because majority of day-to-day care is provided by patients or their family member. Although genetics plays a key role in diabetes development, PWD had shown a positive impact on their disease progression by actively participating in diabetes-related self-care activities ${ }^{38}$ Improvement in diabetes care is of critical importance for developing countries such as Pakistan, which are facing rapidly growing prevalence of diabetes. Reduction in chances of developing diabetesassociated complications is an ultimate target for diabetes self-management. There is a need to know the strong predictors for glycemic control and self-care activities, which can be useful for clinicians and diabetes educators in designing an ideal and patient-tailored diabetes self-management educational program. Additionally, involvement of peer support program may be a cost-effective and promising approach for diabetes self-management education. In our study, we observed HU as an insignificant predictor for glycemic control; this could be due to inadequate time allocation for patients to address all queries related to their diabetes self-care.

\section{Conclusion}

To prevent morbidity and mortality associated with diabetes, patients' dedicated self-care activities are of crucial importance. PWD tend to have good or poor glycemic control depending upon their diabetes-related self-care activities, especially GM and diet intake. Moreover, smoking, low education levels and increased combination of euglycemic agents are key predictors for poor self-care practices.

\section{Strength and limitations}

Use of a validated study tool in native Urdu language for measuring self-care activities is the one of the strengths of the study. Although other studies reported the glycemic control status of Pakistani T2DM patients, this study is the first to examine the association of glycemic control with their selfcare activities. A limitation of the study is its design, as crosssectional study designs evaluate the patients at one point in time, hence cannot examine the change or improvement in patients' glycemic control or self-care practices. Secondly, the term "predict" in this study refers to statistical prediction using regression analyses of concurrent associations between study variables; no causal inference is possible. Another limitation of the study is the potential bias associated with self-reporting of diabetes-related self-care activities by the study participants.

\section{Data sharing statement}

Urdu version of Diabetes Self-management Questionnaire is available online at https://static-content.springer.com/esm/ art\%3A10.1186\%2Fs12955-017-0776-8/MediaObjects/ 129552017776 MOESM2 ESM.pdf. ${ }^{39}$ English version of Diabetes Self-management Questionnaire is available online at https://static-content.springer.com/esm/ art\%3A10.1186\%2Fs12955-017-0776-8/MediaObjects/ 129552017776 MOESM1 ESM.pdf. ${ }^{40}$ 


\section{Acknowledgments}

AB gratefully acknowledges Monash University for providing PhD Merit Scholarship. KGC thanks the grant from the University of Malaya (PG089-2015B).

\section{Disclosure}

The authors report no conflicts of interest in this work.

\section{References}

1. International Diabetes Federation [webpage on the Internet]. IDF Diabetes Atlas 2017. 8th ed. Available from: http://diabetesatlas.org/ resources/2017-atlas.html. Accessed May 29, 2018.

2. International Diabetes Federation [webpage on the Internet]. IDF Diabetes Atlas 2016. 7th ed. Available from: http://www.diabetesatlas. org/. Accessed February 13, 2016.

3. Babazadeh T, Dianatinasab M, Daemi A, Nikbakht HA, Moradi F, Ghaffari-Fam S. Association of self-care behaviors and quality of life among patients with type 2 diabetes mellitus: Chaldoran County, Iran. Diabetes Metab J. 2017;41(6):449-456.

4. Lu Y, Xu J, Zhao W, Han HR. Measuring self-care in persons with type 2 diabetes: a systematic review. Eval Health Prof. 2016;39(2): 131-184.

5. Wändell PE. Quality of life of patients with diabetes mellitus. An overview of research in primary health care in the Nordic countries. Scand J Prim Health Care. 2005;23(2):68-74.

6. Chew BH, Mastura I, Lee PY, Wahyu TS, Cheong AT, Zaiton A. Ethnic differences in glycaemic control and complications: the adult diabetes control and management (ADCM), Malaysia. Med J Malaysia. 2011;66(3):244-248.

7. Stratton IM, Adler AI, Neil HA, et al. Association of glycaemia with macrovascular and microvascular complications of type 2 diabetes (UKPDS 35): prospective observational study. BMJ. 2000;321(7258): 405-412.

8. Feinglos MN, Bethel MA. Type 2 Diabetes Mellitus: An Evidence-Based Approach to Practical Management. Springer Science \& Business Media; 2008.

9. Nwasuruba C, Khan M, Egede LE. Racial/ethnic differences in multiple self-care behaviors in adults with diabetes. J Gen Intern Med. 2007; 22(1):115-120.

10. Xu Y, Pan W, Liu H. Self-management practices of Chinese Americans with type 2 diabetes. Nurs Health Sci. 2010;12(2):228-234.

11. Wabe NT, Angamo MT, Hussein S. Medication adherence in diabetes mellitus and self management practices among type-2 diabetics in Ethiopia. N Am J Med Sci. 2011;3(9):418-423.

12. Compeán Ortiz LG, Gallegos Cabriales EC, González González JG, Gómez Meza MV. Self-care behaviors and health indicators in adults with type 2 diabetes. Rev Lat Am Enfermagem. 2010;18(4):675-680.

13. Ahola AJ, Groop PH. Barriers to self-management of diabetes. Diabet Med. 2013;30(4):413-420.

14. Inzucchi SE, Bergenstal RM, Buse JB, et al; American Diabetes Association (ADA); European Association for the Study of Diabetes (EASD). Management of hyperglycemia in type 2 diabetes: a patient-centered approach: position statement of the American Diabetes Association (ADA) and the European Association for the Study of Diabetes (EASD). Diabetes Care. 2012;35(6):1364-1379.

15. St John A, Davis WA, Price CP, Davis TM. The value of self-monitoring of blood glucose: a review of recent evidence. J Diabetes Complications. 2010;24(2):129-141.

16. Bukhsh A, Khan TM, Lee SWH, Lee LH, Chan KG, Goh BH. Efficacy of pharmacist based diabetes educational interventions on clinical outcomes of adults with type 2 diabetes mellitus: a network meta-analysis. Front Pharmacol. 2018;9:339.
17. Ullah Khan A, Zafar Ali Khan M, Nadeem M, Yasmeen Bangash R, Fakhr A. Status of glycemic control in patients of type 2 diabetes mellitus. Pak Armed Forces Med J. 2013;63(2):205.

18. Khan DA, Saeed M, Khan FA. Is glycemic control in patients with type-2 diabetes in Rawalpindi improving? J Ayub Med Coll Abbottabad. 2009;21(1):62-65.

19. Bukhsh A, Lee SWH, Pusparajah P, Schmitt A, Khan TM. Psychometric properties of the Diabetes Self-Management Questionnaire (DSMQ) in Urdu. Health Qual Life Outcomes. 2017;15(1):200.

20. Daniel W. Biostatistics: A Foundation for Analysis in the Health Sciences. 7th ed. New York: R Wiley; 1999.

21. Bukhsh A, Lee SWH, Pusparajah P, Khan AH, Khan TM. Psychometric properties of the Urdu version of Diabetes Knowledge Questionnaire. Front Public Health. 2017;5:139.

22. Schmitt A, Gahr A, Hermanns N, Kulzer B, Huber J, Haak T. The Diabetes Self-Management Questionnaire (DSMQ): development and evaluation of an instrument to assess diabetes self-care activities associated with glycaemic control. Health Qual Life Outcomes. 2013;11:1 38.

23. Ali MK, Bullard KM, Saaddine JB, Cowie CC, Imperatore G, Gregg EW. Achievement of goals in U.S. diabetes care, 1999-2010. N Engl J Med. 2013;368(17):1613-1624.

24. García-Pérez LE, Álvarez M, Dilla T, Gil-Guillén V, Orozco-Beltrán D. Adherence to therapies in patients with type 2 diabetes. Diabetes Ther. 2013;4(2):175-194.

25. Lee SW, Lee JY, Tan CS, Wong CP. Strategies to make Ramadan fasting safer in type 2 diabetics: a systematic review and network meta-analysis of randomized controlled trials and observational studies. Medicine (Baltimore). 2016;95(2):e2457.

26. Ghasemi A, Zahediasl S. Normality tests for statistical analysis: a guide for non-statisticians. Int J Endocrinol Metab. 2012;10(2):486-489.

27. D'Souza MS, Karkada SN, Venkatesaperumal R, Natarajan J. Self-care behaviours and glycemic control among adults with type 2 diabetes. GSTF J Nurs Health Care. 2017;2(1):29-40.

28. Houle J, Beaulieu MD, Chiasson JL, et al. Glycaemic control and self-management behaviours in type 2 diabetes: results from a 1-year longitudinal cohort study. Diabet Med. 2015;32(9):1247-1254.

29. Franz MJ, Boucher JL, Evert AB. Evidence-based diabetes nutrition therapy recommendations are effective: the key is individualization. Diabetes Metab Syndr Obes. 2014;7:65-72.

30. Gul N. Knowledge, attitudes and practices of type 2 diabetic patients. J Ayub Med Coll Abbottabad. 2010;22(3):128-131.

31. Kassahun T, Gesesew H, Mwanri L, Eshetie T. Diabetes related knowledge, self-care behaviours and adherence to medications among diabetic patients in Southwest Ethiopia: a cross-sectional survey. BMC Endocr Disord. 2016;16(1):28.

32. Ayele K, Tesfa B, Abebe L, Tilahun T, Girma E. Self care behavior among patients with diabetes in Harari, Eastern Ethiopia: the health belief model perspective. PLoS One. 2012;7(4):e35515.

33. Bai YL, Chiou CP, Chang YY. Self-care behaviour and related factors in older people with type 2 diabetes. J Clin Nurs. 2009;18(23): 3308-3315.

34. Huang M, Zhao R, Li S, Jiang X. Self-management behavior in patients with type 2 diabetes: a cross-sectional survey in western urban China. PLoS One. 2014;9(4):e95138.

35. Noureddine H, Nakhoul N, Galal A, Soubra L, Saleh M. Level of A1C control and its predictors among Lebanese type 2 diabetic patients. Ther Adv Endocrinol Metab. 2014;5(3):43-52.

36. D'Souza M, Venkatesaperumal R, Karkada S, Amirtharaj A. Determinants of glycosylated haemoglobin among adults with type 2 diabetes mellitus. J Diabetes Metab. 2013;4(5):1-6.

37. Ashur ST, Shah SA, Bosseri S, Fah TS, Shamsuddin K. Glycaemic control status among type 2 diabetic patients and the role of their diabetes coping behaviours: a clinic-based study in Tripoli, Libya. Libyan J Med. 2016;11:31086.

38. Shrivastava SR, Shrivastava PS, Ramasamy J. Role of self-care in management of diabetes mellitus. J Diabetes Metab Disord. 2013;12(1):14. 
39. Bukhsh A, Khan TM. Psychometric properties of the Diabetes SelfManagement Questionnaire (DSMQ) in Urdu. Health and quality of life outcomes 15.1 (2017): 200. Available from: https://staticcontent.springer.com/esm/art\%3A10.1186\%2Fs12955-017-0776-8/ MediaObjects/12955_2017_776_MOESM2_ESM.pdf. Accessed April 24, 2018.
40. Bukhsh A, Khan TM. Psychometric properties of the Diabetes SelfManagement Questionnaire (DSMQ) in Urdu. Health and quality of life outcomes 15.1 (2017): 200. Available from: https://staticcontent.springer.com/esm/art\%3A10.1186\%2Fs12955-017-0776-8/ MediaObjects/12955_2017_776_MOESM1_ESM.pdf. Accessed April 24, 2018.

\section{Publish your work in this journal}

Patient Preference and Adherence is an international, peer-reviewed, open access journal that focuses on the growing importance of patient preference and adherence throughout the therapeutic continuum. Patient satisfaction, acceptability, quality of life, compliance, persistence and their role in developing new therapeutic modalities and compounds to optimize clinical outcomes for existing disease states are major areas of interest for the journal. This journal has been accepted for indexing on PubMed Central. The manuscript management system is completely online and includes a very quick and fair peer-review system, which is all easy to use. Visit http://www. dovepress.com/testimonials.php to read real quotes from published authors.

\footnotetext{
Submit your manuscript here: http://www.dovepress.com/patient-preference-and-adherence-journal
} 